\title{
INVESTIGATION OF THE INFLUENCE OF FLAXSEED MEAL ON THE BIOCHEMICAL PROCESSES OF THE WHEAT TEST
}

\author{
Orysia Izhevska \\ Department of hotel and restaurant business \\ Lviv State University of Physical Culture named after I. Bobersky \\ 11 T. Kostyushka str., Lviv, Ukraine, 79000 \\ orisyaiz@ukr.net
}

\begin{abstract}
One of the well-known tasks in the organization of nutrition is the development of new bakery products with high nutritional and biological value and wellness properties.

Linen meal is an important source of dietary fiber, high protein, unsaturated fatty acids, minerals and vitamins.

The purpose of the research was to determine the effect of this meal on the depth of the processes occurring in the dough during kneading and maturing.

A linseed meal LLC «Zhytomyrbioproduct» (Ukraine) with a certain chemical composition was used in the research.

The research was conducted to study the effect of flaxseed meal on the kinetics of sugars in the dough during its maturation. The study was performed using an iodometric method, based on the determination of the amount of oxidized copper before and after recovery of the alkaline copper solution with sugar.

It has been established, that the addition of flax seed meal to the dough reduces the amount of sugars, formed during the maturation of the dough, which adversely affects the activity of the dough microflora. This is confirmed by the lower consumption of sugars for fermentation.

The viscosity of water-flour slurry with a flaxseed meal has been investigated. The starch grains are infinitely swollen in the process of increasing temperature of the slurry in the amylograph, and a starch paste is formed, the viscosity of which increases with temperature. At the same time, under the action of flour enzymes, there is a decrease in viscosity due to the hydrolysis of starch.

The results of the researches testify about the effectiveness of the offered methods of studying the rules and depth of processes in the dough with a meal of flax seed during its preparation and maturing, which will allow to increase the yield of the dough and the output of high quality finished products.
\end{abstract}

Keywords: flax meal, sugar kinetics, viscosity, functional products, dough quality.

DOI: $10.21303 / 2504-5695.2019 .00990$

\section{Introduction}

Organization of nutrition for consumers is a priority function of the restaurant industry. Nutrition is an important factor what helps the human body resist the adverse effects of the environment and the diseases of civilization.

The actual task in the organization of nutrition is the development of new types of products with high nutritional and biological value and health properties.

Bakery products have always been considered to be the basis of diets that are available to all segments of the population, therefore, professionals of food and restaurants industry have a task to make these products maximum functional [1].

In conditions of hard competition in the fight for the consumers, the urgent task is to use innovative approaches to nutrition, thus creating new formats in the concepts of restaurant industry.

Innovation is to improve and further develop food technologies that are enriched with wellness. This goal can be achieved by adding natural plant products to the formulations that are rich in biologically active substances and functional properties.

For enriching the physiological value of food products, scientists conduct researches about use of raw materials of oilseeds that have functional properties, in particular, flax and its products of processing [2-5]. Studies of recent years increasingly reveal the chemical composition of flax seeds, its biological value, technological properties, medical and hygienic value [6-8]. 
The meal contains $33.6 \%$ protein, $9-10 \%$ lipids, $37.6 \%$ dietary fiber. After interacting with water, the meal will swell and form mucus, giving it antibacterial and anti-sclerotic properties. Flax meal is the source of most vitamins such as B1, B2, B6, niacin (PP), pantothenic (B3) and folic acid (B9), biotin (B7), tocopherol (vitamin E).Very important is the content of thiamine (B1). This product is a natural source of selenium. The research conducted by scientists at the University of South Dakota (USA) have found that the content of selenium in flax meal varies from 0.13 to $3.06 \mathrm{mg} / \mathrm{kg}$ or an average of more than $1 \mathrm{mg}$ per $1 \mathrm{~kg}$ of product [9].

Reasoning, the establishment of optimal technological parameters of bread preparation, which ensure high quality of finished products, requires exploring of the course of these processes. From the practical point of view, adding a meal of flax seeds to bakery products causes a change in the organoleptic properties [8] of finished products and the structural and mechanical properties of dough and finished products [9].

The specificity of the chemical composition of flax meal, namely the high content of proteins, lipids, dietary fibers requires reasoning of the influence of the inclusion of flax meal in the preparation process of dough. Thus, the research of scientists $[8,10]$ found that the addition of more than $5 \%$ of flax seeds in bakery products causes a change of the organoleptic properties of finished products and structural and mechanical properties of dough and finished products. Adding 2.5-3\% of flax meal to the flour does not affect the quality of bread, but such amount is not enough to enrich the bread with biologically active substances. Dosing more than $10 \%$ of flax meal significantly impairs the technological process and reduces the quality of bread. The reason for these changes may be the influence of the components of the flax seed meal on the course of the fermentation process of the dough. This leads to studying the effects of flax meal on biochemical processes in the dough.

During the maturation of the dough due to the course of interrelated biochemical, microbiological, colloidal and other processes, significant changes occur in the carbohydrate-amylase and protein-proteinase complex of flour, which accumulate sugars, nitrogen and other substances in the dough and provide alcohol and lactic acid fermentation and are precursors of flavoring in dough semi-finished products and finished products.

The depth of these processes define accumulation and fermentation of sugars, the dynamics of formation and excretion of carbon dioxide during the maturation of test semi-finished products, increase of their titrated acidity, $\mathrm{pH}$, organic acids, volatile acids content, changes in the fractional composition of proteins, accumulation of water-soluble nitrogen, activity of a fermenting microflora of dough.

Starch plays an important role in the formation of bread crumbs in the baking process. If starch is able to bind a lot of water, a dry hard crumb forms. If starch binds too much water, a wet blob is formed because some water, released by protein coagulation, remains in the free condition. After analyzing this process, examining the behavior of the water-slurry when heated on an amylograph by changing the viscosity of this slurry in the process of increasing the temperature of warming, you can predict the condition of the bread crumb.

Dough is a multi-component system, so other components are involved in forming the viscosity of the water-flour system, along with starch [8]. Linseed meal has more water absorption capacity than flour, it contains a significant amount of dietary fiber that actively binds water, so it was necessary to investigate the properties of a water-flour suspension, containing linseed meal.

Therefore, the production of bakery products with functional properties is ensured by the introduction of flax seed meal as a raw material with the valuable chemical composition and biologically active substances, but provided the study of the influence of this meal on the course of biochemical processes in the dough and finished products.

The aim of this research is to study the effect of flaxseed meal on the quality of wheat flour dough. It allows to study more deeply the influence of this unconventional raw material on the technological processes of preparation of dough semi-finished products for bread. Considering the specificity of the chemical composition of flax meal, this exploring will help in the selection of technological methods to improve the structural and mechanical properties of dough and finished products, the results of which will be published in subsequent periodical editions. 


\section{Materials and methods}

\section{1. The materials used in the experiment}

The meal of seeds of flax-mezheumka variety Nizhynsky, obtained by the method of "cold pressing" production of LLC "Zhitomirbioproduct" (Zhytomyr region, Ukraine) with a chemical composition containing proteins $32.6 \%$, dietary fibers $37.6 \%$, lipids $10 \%$, was used in the research.

When determining the sugar content, two types of dough are prepared: yeast and yeastless. Preparation of the control sample of yeast dough was carried out in accordance with the recipe for "Bread of wheat" SSTC 7517: 2014 in the following proportions:

- wheat flour first grade $-100 \%$;

- Yeast bakery pressed -3\%;

- kitchen salt $-1 / 5 \%$.

During the exploring, the yeast dough was prepared by the one-phase method without flax seed meal (control) and with the addition of 2.5; 5.0; 7.5 and $10 \%$ of flax seed meal to flour. The moisture content of the dough was $44 \%$. The yeastless dough was prepared according to the same formulation without the use of yeast.

For sedimentation of proteins, $15 \%$ zinc sulfate and $4 \%$ sodium hydroxide was used.

The studied flax meal had the following organoleptic characteristics: a dark brown color, a pleasant nutty smell, and the taste was a little bit bitter-spicy. The groats were felt to the touch.

The size of its particles is not provided in the regulatory documentation about meal. In fact, the market meal has a size of 1000 microns, which is much larger than the size of wheat flour. Therefore, before using it was crushed on a laboratory mill and sieved through a sieve with cells of $0.52 \mathrm{~mm}$. Grinding was carried out because of the size affects the technological properties of the raw material, because if a degree grinding is high, then the contact surface of the raw material with water is bigger and then physical-chemical processes occur more actively. Meal was added to the appropriate samples at the kneading stage of the dough.

\section{2. Methods for determining biochemical parameters}

Appropriate techniques were used («Iodometric method for determining sugars (semi-micromethods)», «Method for determining the viscosity of a water-flour suspension on amylographs».

These techniques were used to study the effects of flax meal on biochemical processes occurring in the dough.

The intensity of the fermentation processes and the formation of coloring of the crust of bread due to the Mayer reaction depend on accumulation of sugars in the dough during its maturation.

And analyzing the behavior of the water-flour suspension during heating on an amylograph by changing the viscosity of the suspension in the process of increasing the temperature of heating assumes the condition of the bread crumb.

The research was conducted in the laboratory of clinical and biological research of the State Research Institute of Veterinary Drugs and Feed Additives (Lviv, Ukraine), the laboratories of the Department of Baking and Confectionery Technology of the National University of Food Technologies (Kyiv, Ukraine), the biochemical laboratory in University of physical culture, named after I. Bobersky (Lviv, Ukraine).

\section{2. Determination of the influence of flaxseed meal on the kinetics of sugars during}

\section{maturation}

The meaning of the method is to determine the amount of oxidized copper before and after the recovery of the alkaline copper solution with sugar [11].

During the research, the yeast dough is prepared in a one-phase way without flax seed meal (control) and with the addition of $2.5 ; 5.0 ; 7.5$ and $10 \%$ of flax seed meal to flour. Such proportions in the limit of $10 \%$ were taken to determine the more accurate regularity of the influence of the flax seed meal on the test specimens, because, according to established data [8-10], the dosage of flax meal more than $10 \%$ significantly worsens the technological process and reduces the quality of bread. The duration of fermentation of the dough was 4 hours with the temperature of $30{ }^{\circ} \mathrm{C}$. 
To determine the sugar content of the prepared samples, $10 \mathrm{~g}$ of the semi-finished product is taken, ground with $100 \mathrm{~cm}^{3}$ of distilled water and quantitatively transferred to a $200-\mathrm{ml}$ volumetric flask and mixed. For sedimentation of proteins, $10 \mathrm{~cm}^{3}$ of $15 \%$ zinc sulfate is poured, and during stirring $-10 \mathrm{~cm}^{3}$ of $4 \%$ sodium hydroxide also is poured. The contents of the flask were well shaken and remained for 15 minutes. The precipitated liquid is filtered into a dry flask. In filtrate the mass fraction of directly reducing sugars is determined. The sugar content is determined by the iodometric (accelerated) method.

The amount of sugars, formed during the maturation of the dough, was determined by the difference between their content in the yeastless dough after mixing and after $4 \mathrm{~h}$ of its fermentation.

The amount of fermented sugars was determined by difference between the amount of sugars in the yeast dough after mixing and the amount of sugars, formed in the yeastless dough, and the amount of sugars, contained in the yeast dough after $4 \mathrm{~h}$ of fermentation.

\section{2. 2. Investigation of the viscosity of a water-flour suspension with a flax seed meal} on amylograph

The research of viscosity of the water-flour suspension with a flax seed meal were carried out at Amylograph-E of Brabender company(Germany)

In the course of the research, a suspension was prepared according to the instruction in the device $[11,12]$. Flax seed meal was added to flour in the suspension in the amount of 2.5; 5.0; 7.5 and $10 \%$.The control was a suspension without meal. For the research, a suspension of $80 \mathrm{~g}$ of flour and $450 \mathrm{~cm}^{3}$ of water is prepared in a special vessel, stirring it with a hand stirrer, which is added to the device, during 1.5 minutes.

The slurry was transferred to the working capacity of the amylograph, in which, during continuous rotation, it warmed from the initial temperature of $25^{\circ} \mathrm{C}$ to $90{ }^{\circ} \mathrm{C}$ with speed $1.5^{\circ} \mathrm{C} / \mathrm{min}$.

The maximum viscosity of the suspension is determined by height of the viscosity curve (amylogram) of the water-flour suspension which is recorded. The beginning temperature of gelatinization (increasing its viscosity) was also recorded.

\section{Results of biochemical studies}

\section{1. The results of determining the effect of flaxseed meal on the kinetics of sugars during maturation}

The results of studies of the effects of meal on the kinetics of sugars are shown in Table 1.

It was found, that in the samples with the addition of flax seed meal during the fermentation, less sugars were formed than in the control sample if more flax seed meal was added into the dough.

Table 1

Accumulation and fermentation of sugars in the process of fermentation of the dough, $\%$ on dry substances

\begin{tabular}{cccccc}
\hline Indexes & \multirow{2}{*}{ Control } & \multicolumn{3}{c}{ Flax seed meal (FSM), \% by weight of flour } \\
\cline { 3 - 6 } & \multicolumn{2}{c}{ Yeastless dough } & $\mathbf{5 . 0}$ & $\mathbf{7 . 5}$ & $\mathbf{1 0}$ \\
\hline Sugar content after mixing & 2.22 & 2.21 & 2.23 & 2.22 & 2.24 \\
After 4 h of fermentation & 4.60 & 4.53 & 4.51 & 4.41 & 4.39 \\
Sugars what were formed & 2.38 & 2.32 & 2.28 & 2.19 & 2.15 \\
\hline After mixing & Yeast dough & & & \\
\hline After 4 h of fermentation & 2.24 & 2.20 & 2.23 & 2.21 & 2.22 \\
Fermented sugars & 2.55 & 2.58 & 2.70 & 2.68 & 2.71 \\
\end{tabular}

Thus, compared to the control sample, less sugar was formed in the dough with $2.5 \%$ of flax seed meal on 2.6; from 5.0-on 4.3; 7.5-on 8.1; from 10 - on $9.7 \%$. This indicates that the addition 
of meal to the dough leads to a decrease of ammolysis starch susceptibility due to the formation of complexes of starch grains and mucus.

Along with the decrease in the formation of sugars in the test with FSM, their digestion decreases by the dough microflora by 8.7-19.2\%, depending on the amount of flax seed meal added, what is a consequence of the deterioration of the composition of the nutrient medium for yeast cells and a decrease in their fermentation activity with the presence of mucus of flax meal.

\section{2. The results of the research of the viscosity of the water-flour suspension with a flax seed meal on the amylograph \\ In the process of increasing the temperature of the suspension in the amylograph starch} grains are infinitely swollen, a starch paste is formed, the viscosity of which increases with temperature. At the same time, because of action of flour enzymes, there is a decrease in viscosity due to the hydrolysis of starch.

These opposing processes are affected by the addition of raw material, which is reflected in the shape of the curve of the amylograph.

The results of decoding the curves of the amylogram are presented in Table 2.

Table 2

Indicators of amylograms of the investigated suspensions

\begin{tabular}{cccc}
\hline Water-flour suspensions & $\begin{array}{c}\text { Time before starch } \\
\text { glutinization (viscous } \\
\text { system formation), min }\end{array}$ & $\begin{array}{c}\text { Starting temperature } \\
\text { for starch glutinization } \\
\text { (viscous system } \\
\text { formation), }\end{array}$ & $\begin{array}{c}\text { Maximum system } \\
\text { viscosity, units of } \\
\text { device }\end{array}$ \\
\hline $\begin{array}{c}\text { Control (without FSM) } \\
\text { With the addition of FSM, \%to weight of flour: }\end{array}$ & 12 & 53.5 & 505 \\
2.5 & 10 & 50.5 & 540 \\
5.0 & 9 & 49.0 & 580 \\
7.5 & 8 & 47.5 & 660 \\
10.0 & 7.5 & 46.5 & 720
\end{tabular}

Flaxseed meal slurries, compared to controls, acquire viscous properties earlier in 2$4.5 \mathrm{~min}$ and at a lower temperature by $3-7^{\circ} \mathrm{C}$. The maximum viscosity of these systems is higher by $7-42.5 \%$.

So the specified indicators of the amylogram vary depending on the amount of flax seeds, introduced into the meal system. This can be explained by the fact that the soluble dietary fibers of flax meal swell faster than the starch glutinization begins, which causes the acceleration of formation of the viscous system.

In the control sample, the viscosity increases due to the deepening of the starch gelatinization with increasing temperature and reaches a maximum when it is completely gelatinized.

In the test specimens, after temperature rises to the maximum viscosity, along with the deepening of the starch gelatinization, affects the swelling of soluble and insoluble dietary fiber, which causes an increase in the viscosity of the slurry with flax seed meal.

Thus, due to the increased absorption of water by the ingredients of the meal and the formation of mucus complexes with starch, while baking starch grains are not able to bind sufficient water, resulting of this is a less elastic crumb, which was reported in studies [8-10].

\section{Conclusions}

In dough with flax seed meal due to the formation of complexes of starch with mucus, its amylolysis susceptibility deteriorates, which causes a decrease of $2.6-9.7 \%$ of the amount of sugars, formed during the maturation of the dough and adversely affects the activity of the microflora of the dough. This is confirmed by a lower consumption of sugars for fermentation by $8.7-19.2 \%$. 
According to the data, obtained on the amylograph, due to the high water absorption capacity of dietary fiber and flax meal proteins, formation of mucus during heating the water-flour suspension what contains flax seed meal, acquires viscous properties earlier in 2-4.5 minutes and at a lower temperature by $3-7^{\circ} \mathrm{C}$, reaches a maximum of $7-42 \%$ of the maximum viscosity, which is reflected in the elasticity of the bread crumb, enriched with a linseed meal.

Flax seed meal is recommended to be added to food formulations, especially in bakery products, to solve problems of replenishing the diet with functional ingredients that not only provide nutrients, but also contribute to the prevention and treatment of diseases.

But the flax meal, like most non-traditional raw materials, does not provide the preservation of the traditional quality of bakery products, which further requires the use of certain technological methods.

\section{References}

[1] Bogatyrev, A. N., Makeeva, I. A. (2014). Problems and prospects of natural food products production. Pishchevaya promyshlennost', 2, 8-10.

[2] De la Hera, E., Ruiz-París, E., Oliete, B., Gómez, M. (2012). Studies of the quality of cakes made with wheat-lentil composite flours. LWT, 49 (1), 48-54. doi: https://doi.org/10.1016/j.lwt.2012.05.009

[3] Inglett, G. E., Chen, D., Lee, S. (2013). Rheological Properties of Barley and Flaxseed Composites. Food and Nutrition Sciences, 04 (01), 41-48. doi: https://doi.org/10.4236/fns.2013.41007

[4] Wang, Y., Li, D., Wang, L.-J., Li, S.-J., Adhikari, B. (2010). Effects of drying methods on the functional properties of flaxseed gum powders. Carbohydrate Polymers, 81 (1), 128-133. doi: https://doi.org/10.1016/j.carbpol.2010.02.005

[5] Rubilar, M., Gutiérrez, C., Verdugo, M., Shene, C., Sineiro, J. (2010). Flaxseed as a source of functional ingredients. Journal of Soil Science and Plant Nutrition, 10 (3), 373-377. doi: https://doi.org/10.4067/s0718-95162010000100010

[6] Meleshkina, E. P. (2016). The scientific approach to flax seeds processing based on the use of their phytochemical potential for creating of new food products with desired properties. Agrarian Reporter of South-East, 1-2, 68-71. Available at: https://www. arisersar.ru/Agrovestnik/vestnik_2016.pdf

[7] Kaur, M., Singh, V., Kaur, R. (2017). Effect of partial replacement of wheat flour with varying levels of flaxseed flour on physicochemical, antioxidant and sensory characteristics of cookies. Bioactive Carbohydrates and Dietary Fibre, 9, 14-20. doi: https://doi.org/10.1016/j.bcdf.2016.12.002

[8] Drobot, V. I., Izhevska, O. P., Bondarenko, J. V. (2015). Effect of flax shrot to the quality of bread. Zernovi produkty ta kombikormy, 1 (57), 42-45. doi: https://doi.org/10.15673/2313-478x.57/2015.39738

[9] Kaur, A., Kaur, R., Bhise, S. (2018). Baking and sensory quality of germinated and ungerminated flaxseed muffins prepared from wheat flour and wheat atta. Journal of the Saudi Society of Agricultural Sciences. doi: https://doi.org/10.1016/j. jssas.2018.07.002

[10] Begeulov, M. Sh., Sycheva, Ye. O. (2017). Breadmaking technology based on using linseed cake. Izvestiya Timiryazevskoy sel'skohozyaystvennoy akademii, 3, 110-126.

[11] Drobot, V. I. (2006). Laboratornyi praktykum z tekhnolohiyi khlibopekarskoho ta makaronnoho vyrobnytstva. Kyiv: Tsentr navchalnoi literatury, 341.

[12] Metodicheskie ukazaniya dlya raboty na amilografe (1976). Moscow: Pishchevaya promyshlennost', 30. 